\title{
Viscocanalostomy versus trabeculectomy for primary open angle glaucoma: 4-year prospective randomized clinical trial
}

'St James's University Hospital, Leeds, UK

${ }^{2}$ York District Hospital, York, UK

${ }^{3}$ Bradford Infirmary, Bradford, UK

${ }^{4}$ Royal Free Hospital, London, UK

${ }^{5}$ University of York, York, UK

Correspondence:

DF Gilmour, Department of Ophthalmology, St James's University Hospital, Beckett Street, Leeds LS9 7TF, UK Tel: + 44 1132433144; Fax: + 441133926239 .

E-mail: gilmour.david@ gmail.com

Received: 26 June 2006 Accepted in revised form: 23 December 2006

Pubished online: 9 February 2007

Financial support: The study was carried out within the National Health Service (NHS). No extra financial support was sought or needed to complete the study

\begin{abstract}
Aims The purpose of this randomized clinical trial was to compare the effectiveness and safety of viscocanalostomy (visco) with trabeculectomy (trab) in the management of primary open angle glaucoma (POAG). Methods Patients were randomized to have a viscocanalostomy (25 eyes) or a trabeculectomy (25 eyes) performed by one surgeon (TDM) and followed up prospectively. Patients were examined preoperatively, at day 1 , day 3 if required, day 6 , week 2 and thereafter as near as possible to $1,3,6,12,18,24,30,36,48,54$, and 60 months. We recorded intraocular pressure (IOP), presence or absence of any complications, presence and description of any bleb, visual acuity with glasses, and full examinations as routine to monitor any progression of the glaucoma. Bleb interventions including needling and antimetabolites were allowed and recorded in both groups. YAG laser goniopuncture was allowed in the viscocanalostomy group. Results Mean follow-up was $\mathbf{4 0}$ months (SD 15), with a range from 6 to 60 months. Forty-two percent $(n=10)$ of the patients in the trabeculectomy group had a successful outcome (IOP $<18 \mathrm{~mm} \mathrm{Hg}$ with no treatment) at last follow-up visit, compared to $21 \%(n=5)$ in the viscocanalostomy group. IOP was lower in the trab group with differences in IOP being statistically significant at month 12 $(P=<0.001), 24(P=<0.001), 30(P=0.030)$, $36(P=<0.001)$, and $48(P=0.018)$. The trabeculectomy group required less postoperative topical IOP-lowering medication $(P=0.011)$.
\end{abstract}

DF Gilmour ${ }^{1}$, TD Manners'2, H Devonport ${ }^{3}$, Z Varga ${ }^{2}$, AL Solebo ${ }^{4}$ and J Miles ${ }^{5}$
Conclusion In this study, we found trabeculectomy to be more effective at lowering IOP than viscocanalostomy in POAG patients.

Eye (2009) 23, 1802-1807; doi:10.1038/sj.eye.6702726; pubished online 9 February 2007

Keywords: viscocanalostomy; trabeculectomy; intraocular pressure; open angle glaucoma

\section{Introduction}

The current surgical treatment of choice for medically uncontrolled glaucoma is trabeculectomy, which was introduced by Cairns in 1968. ${ }^{1}$ However, this procedure is associated with both early and late postoperative complications. Early postoperative problems including hyphaema, fibrinous uveitis, shallow anterior chamber and hypotony (with the risk of choroidal detachment and maculopathy) have been recorded. Late complications include bleb-related problems such as delayed leaks and endophthalmitis and cataract formation. There is evidence that modern trabeculectomy under subspecialist care with releasable sutures reduces the complication rate and increases the probability of success. ${ }^{2}$ In a parallel attempt to reduce complications, non-penetrating filtering procedures have been developed. They differ from trabeculectomy in that there is no sclerostomy, but instead the inner wall of Schlemm's canal and Descemet's membrane remains to act as an outflow resistance site, which reduces the risk of postoperative hypotony. Peripheral iridectomy is not 
performed, thus minimizing risk of hyphaema and postoperative inflammation.

The two major variations are deep sclerectomy (DS) and viscocanalostomy. Viscocanalostomy, described by Stegmann, ${ }^{3}$ is reported to lower intraocular pressure (IOP) without creating a filtering bleb, thus avoiding bleb-related complications. We present the results of our ongoing prospective randomized comparative clinical study comparing viscocanalostomy with trabeculectomy in the management of primary open angle glaucoma (POAG).

\section{Materials and methods}

\section{Patient selection}

We obtained Ethics Committee approval for our study, and all patients gave fully informed consent. Patients were recruited from the Ophthalmology outpatient clinics at the York District Hospital. Fifty eyes of 43 patients were enrolled to this study and followed up prospectively. The inclusion criteria were the diagnosis of POAG or pseudoexfoliation glaucoma with clinical indication for surgery, that is progression of disease as a result of inadequate response to, intolerance of or non-compliance with medical therapy. Exclusion criteria were previous ocular surgery or indication for use of antimetabolite (age less than 50, over 5 years on multiple medications, previous conjunctival surgery and black race). A total of 25 cards for each operation were randomly pulled out of a box by an independent observer and recorded to achieve equal numbers in each group. Demographics, mean preoperative IOPs, visual acuity with glasses (BCVA) and mean number of medications for the two groups are detailed in Table 1.

\section{Surgical technique}

All surgeries were performed by a single surgeon (TDM), and the type of anaesthetic was determined by patient suitability. If local anaesthesia was used, it was a combination of topical oxybuprocaine and

Table 1 Demographics and preoperative data

\begin{tabular}{lccc}
\hline & Trab & Visco & Both \\
\hline Number of patients & 21 & 22 & 43 \\
Mean age (SD) & $64.3(10)$ & $64.5(10.8)$ & $64.4(10.3)$ \\
Male sex (\%) & $15(71 \%)$ & $14(64 \%)$ & $29(67 \%)$ \\
Mean preoperative & $25.3(4.1)$ & $25(4)$ & $25.15(4)$ \\
IOP (SD) & & & \\
Mean preoperative & $0.13(0.22)$ & $0.08(0.19)$ & $0.10(0.21)$ \\
$\quad$ log MAR VA (SD) & & & \\
$\begin{array}{c}\text { Mean number of } \\
\text { medications (SD) }\end{array}$ & $1.38(0.5)$ & $1.43(0.5)$ & \\
\hline
\end{tabular}

Abbreviations: IOP, intraocular pressure; SD, standard deviation; Trab, trabeculectomy; VA, visual acuity; Visco, viscocanalostomy. subconjunctival lignocaine $1 \%$ with adrenaline. All patients under general anaesthesia also received subconjunctival lignocaine $1 \%$ with adrenaline, to make the tissues easier to handle and to standardize this part of the surgery. A corneal traction suture was placed if the patient had difficulty maintaining downward gaze under local anaesthesia, and as routine for general anaesthesia.

\section{Trabeculectomy}

Trabeculectomy was performed using a technique developed from that of Cairns, ${ }^{1}$ with which the surgeon was very familiar. A fornix-based conjunctival flap was fashioned. After wet-field cautery a scleral flap $4 \mathrm{~mm} \times 2 \mathrm{~mm}$ was raised. A paracentesis was done, and the full sclerostomy was made with a single bite of a Khaws Descemet membrane punch (Duckworth \& Kent ${ }^{\mathbb{R}}$, Baldock, Hertfordshire, England). Peripheral iridectomy was done, and the scleral flap sutured with 10/0 nylon (Alcon ${ }^{\circledR}$, Hemel Hempstead, Hertfordshire, England). One releasable suture and a variable number of interrupted sutures were placed, depending on the tested flow through the flap. Tenons and conjunctiva were sutured separately with 10/0 Vicryl. Atropine drops were instilled.

\section{Viscocanalostomy}

The surgeon had previously undertaken training in viscocanalostomy technique, and had performed 10 cases over the previous year with patients consent as part of a learning curve. The technique was that described by Stegmann. ${ }^{3}$ A fornix-based conjunctival flap was fashioned, and very light cautery was done, avoiding if possible aqueous collector veins. A one-third thickness scleral flap was raised extending into clear cornea. A second near-full thickness flap was made $1 \mathrm{~mm}$ inside this flap and slowly extended into Schlemms canal, after paracentesis. A Descemets window was exposed with pressure from a cellulose sponge. A good ooze of aqueous was achieved, if necessary by stripping thin layers of deep tissue overlying Schlemm's canal and Descemet's membrane with fine forceps. The deep flap was excised with scissors. Balanced salt solution was injected into Schlemm's canal to confirm its position, followed by gentle dilation of the cut ends of Schlemm's with Healon GV (AMO ${ }^{\circledR}$, High Wycombe, Bukinghamshire, England). The superficial flap was secured in as watertight fashion as possible with 10/0 Vicryl. Healon GV was injected into the subscleral lake, and the tenons and conjunctiva sutured as the trabeculectomy group.

\section{Both groups}

Subconjunctival injections of betamethasone and vancomycin were given in the inferior fornix. Topical 
chloramphenicol was applied six times daily for 5 days, and $1 \%$ prednisolone acetate six times daily for 1 week, before gradual reduction over the next 8 weeks.

Patients were examined preoperatively, at day 1 , day 3 if required, day 6 , week 2 and thereafter as near as possible to $1,3,6,12,18,24,30,36,42,48,54$, and 60 months. We recorded IOP, presence or absence of any complications, presence and description of any bleb, visual acuity with glasses, and full examinations as routine to monitor any progression of the glaucoma. Bleb interventions including needling and antimetabolites were allowed and recorded in both groups. YAG laser goniopuncture was allowed in the viscocanalostomy group.

The operation was deemed a success if IOP was below $18 \mathrm{~mm} \mathrm{Hg}$ without treatment. If the IOP was below $18 \mathrm{~mm} \mathrm{Hg}$ with or without topical treatment then this was defined as qualified success. If the IOP was above $18 \mathrm{~mm} \mathrm{Hg}$ on treatment, or if a further operation was needed to control IOP then this was defined as failure.

\section{Statistical analysis}

The analysis was carried out to compare the mean IOP scores at each time point. As each individual may contribute one or two eyes to the analysis, the independence assumption is violated, and it is therefore necessary to apply a modified statistical technique, which is able to take this into account. ${ }^{4}$ The approach used was that of generalized estimating equations (GEE) as implemented within the GEEpack add-on of the statistical package R 2.0. In addition, Kaplan-Meier survival curves were drawn and compared across groups using a log rank test. GEE was also used for this part of the analysis. Continuous variables were compared with a $t$-test, and $95 \%$ confidence intervals of the difference, ordinal variables were compared using a Mann-Whitney $U$ test, and categorical dichotomous variables were compared using a Pearson $\chi^{2}$ test, with an odds ratio, and $95 \%$ confidence intervals. An alpha value of 0.05 was used throughout.

\section{Results}

Fifty eyes of 43 caucasian patients (28 male, 15 female) underwent surgery from March 2000 until February 2004. Patients with two eyes enrolled at different dates were treated as two separate entries to the trial and agreed randomization for the second eye. All patients had POAG, except one in the viscocanalostomy group who had pseudoexfoliation. Mean follow-up was 40 months (SD 15), with a range from 6 to 60 months. One patient in the trabeculectomy group was lost to follow-up and one patient in the viscocanalostomy group died 6 months following surgery.

The trabeculectomy group had a greater decrease in IOP in the initial months following surgery when compared to the viscocanalostomy group, and this lower IOP was sustained throughout the follow-up period (Figure 1). Table 2 illustrates the difference in mean IOP between the two groups at each follow-up visit. Differences in IOP were statistically significant at months $12,24,30,36$ and 48. The difference in mean BCVAs between the two groups did not change significantly throughout the follow-up period.

Using the previous definitions of success and failure, $42 \%(n=10)$ of the patients in the trabeculectomy group had a successful outcome (IOP $<18 \mathrm{~mm} \mathrm{Hg}$ with no treatment) at last follow-up visit, compared to $21 \%$ $(n=5)$ in the viscocanalostomy group $\left(\chi^{2}=3.3, \mathrm{df}=2\right.$, $P=0.194) .79 \%(n=19)$ of patients in each group achieved qualified success (IOP $<18$ with or without topical treatment). Using $21 \mathrm{~mm} \mathrm{Hg}$ as a cutoff for defining success (as with most previous surgery-related glaucoma studies) the success rates were 46 and $21 \%$, with qualified success rates of 83 and $92 \%$, for trabeculectomy and viscocanalostomy, respectively $\left(\chi^{2}=5.378, \mathrm{df}=2, P=0.068\right)$.

The mean number of treatments decreased from 1.38 to 0.67 in the trabeculectomy group, and 1.43 to 1.25 in the viscocanalostomy group. The difference in number of treatments postoperatively was statistically significant $(P=0.011)$. The mean percentage decrease in IOP measured at last follow-up was $35 \%$ for trabeculectomy and $31 \%$ for viscocanalostomy. However $83 \%$ of the viscocanalostomy patients required additional topical treatment to achieve this, compared with $50 \%$ in the trabeculectomy group. Figure 2 shows the cumulative probability of complete success (Figure 2a), and qualified success (Figure $2 \mathrm{~b}$ ) over time for the trabeculectomy and viscocanalostomy groups based on Kaplan-Meier survival analysis. The trabeculectomy group shows an increased probability of complete success. For qualified success there is little difference. Neither of these findings was statistically significant.

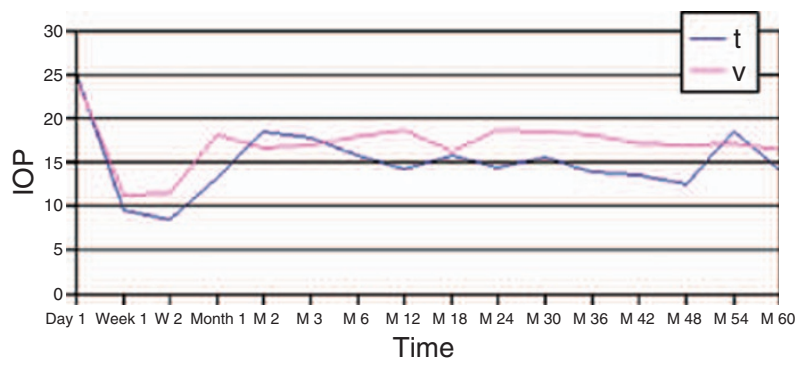

Figure 1 Mean IOP measurements over time following trabeculectomy and viscocanalostomy. 
Table 2 Mean IOPs at each follow-up visit (with number of patients examined) for the two groups

\begin{tabular}{|c|c|c|c|c|c|}
\hline \multirow[t]{2}{*}{ Time } & \multicolumn{2}{|r|}{ Trab } & \multicolumn{2}{|r|}{ Visco } & \multirow[t]{2}{*}{ Difference in IOP (cluster corrected P-value) } \\
\hline & $\mathrm{N}$ & Mean IOP (SD) & $\mathrm{N}$ & Mean IOP (SD) & \\
\hline Day 1 & 23 & 9.61 & 23 & 11.22 & $1.61(0.298)$ \\
\hline Week 1 & 15 & $8.47(5.04)$ & 16 & $11.50(6.03)$ & $3.03(0.127)$ \\
\hline Week 2 & 12 & $13.25(6.84)$ & 13 & $17.69(5.84)$ & $4.44(0.075)$ \\
\hline Month 1 & 21 & $18.52(7.74)$ & 22 & $16.45(4.69)$ & $2.07(0.295)$ \\
\hline Month 3 & 23 & $17.78(6.83)$ & 21 & $16.86(3.32)$ & $0.925(0.555)$ \\
\hline Month 6 & 21 & $15.62(5.22)$ & 21 & $17.90(4.44)$ & $2.29(0.106)$ \\
\hline Month 12 & 14 & $14.29(3.00)$ & 22 & $18.55(3.76)$ & $4.26(<0.001)$ \\
\hline Month 18 & 12 & $16.00(2.13)$ & 22 & $16.27(5.90)$ & $0.27(0.857)$ \\
\hline Month 24 & 16 & $14.38(2.75)$ & 18 & $18.67(3.83)$ & $4.30(<0.001)$ \\
\hline Month 30 & 11 & $15.45(3.96)$ & 15 & $18.47(2.97)$ & $3.02(0.030)$ \\
\hline Month 36 & 9 & $13.89(2.31)$ & 15 & $18.15(3.87)$ & $4.26(<0.001)$ \\
\hline Month 42 & 6 & $13.50(3.67)$ & 13 & $17.27(4.17)$ & $3.77(0.058)$ \\
\hline Month 48 & 4 & $12.50(2.38)$ & 11 & $16.83(3.76)$ & $4.33(0.018)$ \\
\hline Month 54 & 7 & $18.43(3.99)$ & 6 & $17.00(3.85)$ & $-1.42(0.467)$ \\
\hline Month 60 & 1 & 14.00 & 8 & $16.88(2.36)$ & $2.88 \mathrm{NA}$ \\
\hline
\end{tabular}

Abbreviations: IOP, intraocular pressure; Trab, trabeculectomy; Visco, viscocanalostomy.

Intra-operative complications were uncommon (Table 3) and were not associated with a poor outcome. We had three Descemets tears (small perforations into the anterior chamber without iris prolapse) in the viscocanalostomy group that did not require conversion to a fully penetrating procedure. Early postoperative complications are summarized in Table 4 . The trabeculectomy group had higher rates of hypotony ( $<6 \mathrm{~mm} \mathrm{Hg}$ on day 1), choroidal detachment, hypotonous maculopathy and wound leak. At month 1, $19(79 \%)$ of patients in the trabeculectomy group were noted to have conjunctival blebs, compared to $16(64 \%)$ in the viscocanalostomy group. At month 12, 19 of the trabeculectomy patients had conjunctival blebs, with the figure decreasing to 14 in the viscocanalostomy group.

Needling of the wound site was required in seven (29\%) of the trabeculectomy patients (five with 5-fluorouracil) and in one viscocanalostomy patient (with 5-fluorouracil). One patient in the viscocanalostomy group underwent goniopuncture, and three patients in the study group required cataract surgery, all of them were in the viscocanalostomy group.

\section{Discussion}

The findings of the study suggested that trabeculectomy was more effective than viscocanalostomy at lowering IOP during the follow-up period of the trial (mean 40 months). Early postoperative complications were greater in the trabeculectomy group but these did not have a significant influence on outcome and mean change in BCVAs did not differ between the two groups. No significant late complications were recorded in either group. Cataract surgery rates were higher in the viscocanalostomy group, which is unexpected as trabeculectomy is known to be associated with increased rates of cataract surgery, and viscocanalostomy, as a less invasive procedure, may be thought to be less 'cataractogenic'. There are not enough numbers in this trial to make any valid conclusions regarding this.

More bleb manipulations and antimetabolites (5-fluorouracil) were necessary in the trabeculectomy group during follow-up. This is to be expected as it is not the aim of viscocanalostomy to raise a bleb. It has been postulated that viscocanalostomy works by re-establishing drainage via the cut ends of Schlemms canal, ${ }^{3}$ in much the same way as originally claimed for trabeculectomy. ${ }^{5}$ Many of our patients did develop blebs, common with other reports on this procedure. If there was a bleb then we did allow manipulation of this in the viscocanalostomy group, and this was done in one patient. There was a possibility for bias here in that evidence for the nature and timing of postoperative manipulations after viscocanalostomy is still lacking, whereas the authors had considerable experience in the handling and manipulation of wound healing after trabeculectomy.

One experienced glaucoma surgeon carried out the surgery on all the patients. Before randomization there was a 'learning curve' period, where the surgeon performed viscocanalostomy on a series of 10 patients. Although intra-operative complications were very low in both groups, we do appreciate that the surgeon had more experience in trabeculectomy surgery and that this may have influenced long-term outcomes. Other studies have quoted goniopuncture rates between 13 and 37\% post viscocanalostomy ${ }^{6,7}$ which is appreciably higher than in our group of patients where only one patient required 

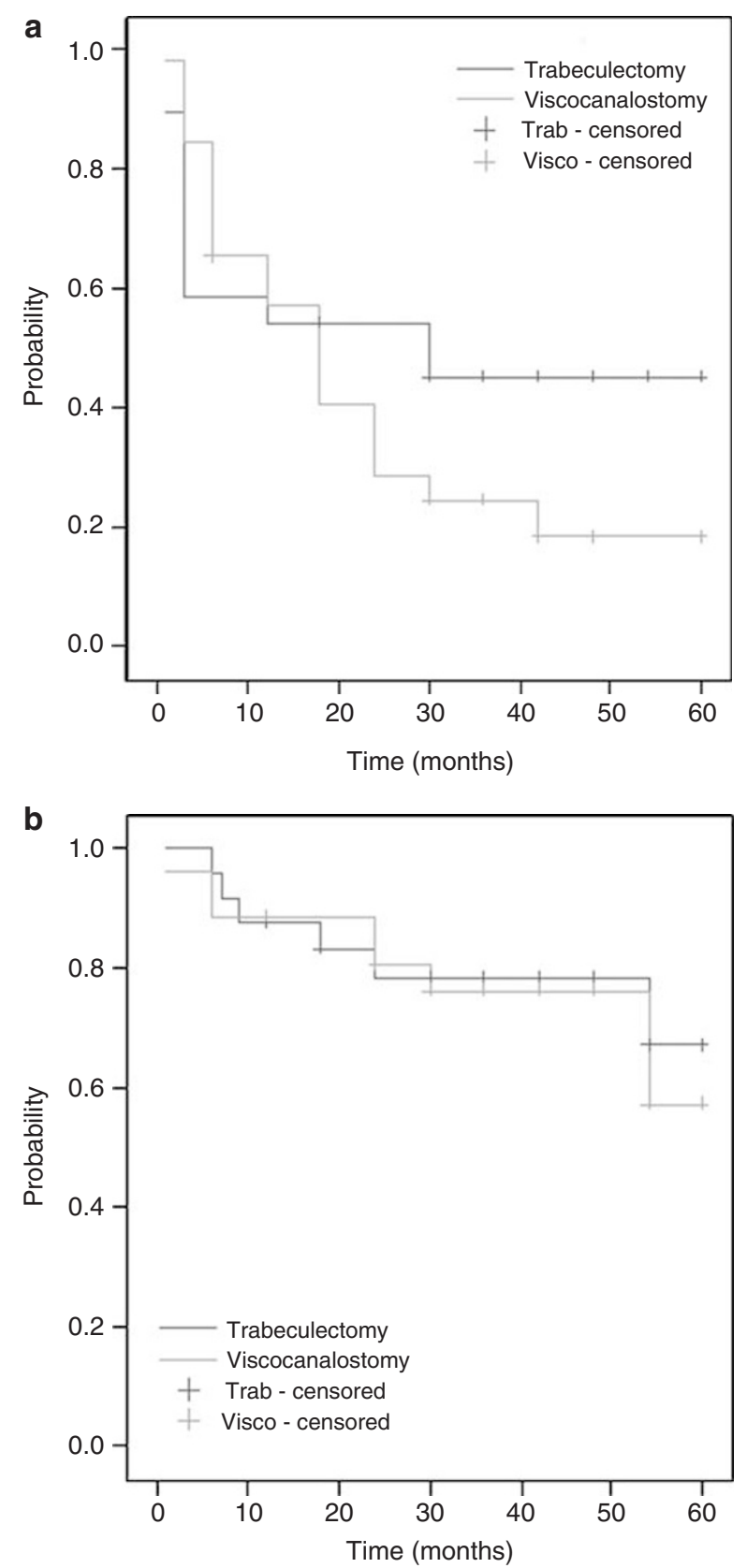

Figure 2 (a) Cumulative probability of complete success (IOP below $18 \mathrm{~mm} \mathrm{Hg}$ without medication) in eyes having trabeculectomy and viscocanalostomy $(P=0.3063)$. (b) Cumulative probability of qualified success (IOP below $18 \mathrm{~mm} \mathrm{Hg}$ with or without medication) in eyes having trabeculectomy and viscocanalostomy $(P=0.7459)$.

the procedure. Shaarawy et $a l^{7}$ suggest goniopuncture if there is insufficient percolation of aqueous humour at the trabeculo-Descemet's membrane. In this study, which looked at results of viscocanalostomy only, complete success (IOP $<21 \mathrm{~mm} \mathrm{Hg}$ without medication) was achieved in $60 \%$ of patients at 60 months, with a qualified
Table 3 Intra-operative complications

\begin{tabular}{lccc}
\hline & $\begin{array}{c}\text { Re-positioning } \\
\text { of scleral flap }\end{array}$ & Hyphaema & $\begin{array}{c}\text { Descemet's } \\
\text { tear }\end{array}$ \\
\hline Trab & 0 & 1 & 0 \\
Visco & 1 & 0 & 3 \\
\hline
\end{tabular}

Abbreviations: Trab, trabeculectomy; Visco, viscocanalostomy.

success rate (IOP below $21 \mathrm{~mm} \mathrm{Hg}$ with or without medication) of $90 \%$. A more aggressive approach to postoperative management in our group of viscocanalostomy patients may have resulted in lower IOP rates.

We defined success following the procedure as an IOP of below $18 \mathrm{~mm} \mathrm{Hg}$ without treatment. Many previous glaucoma studies have used $21 \mathrm{~mm} \mathrm{Hg}$ as a cutoff for defining complete success. We felt that using $18 \mathrm{~mm} \mathrm{Hg}$ for our analysis would be more helpful to the practicing clinician, as this is a more appropriate target pressure following glaucoma surgery. A total of $79 \%$ of patients in each group achieved qualified success at last follow-up, with a greater proportion of trabeculectomy patients achieving complete success.

Yalvac et $a l^{8}$ and Carassa et $a l^{9}$ conducted similar studies comparing the two operations with shorter follow-up times of 3 and 2 years, respectively. They both found trabeculectomy to be more effective than viscocanalostomy at lowering IOP, but with higher complication rates in the trabeculectomy group. O'Brart et $a l^{6,10}$ have conducted two randomized controlled trials, one comparing augmented trabeculectomy with viscocanalostomy, and the other comparing augmented trabeculectomy with augmented viscocanalostomy. In both, trabeculectomy performed better than viscocanalostomy with regard to IOP control. Other non-penetrating filtration techniques have been developed, of which DS is the most promising. Mermoud et $a l^{11}$ compared DS (and collagen implant) with trabeculectomy and showed success rates (IOP $<21 \mathrm{~mm}$ $\mathrm{Hg}$ without medication) of $69 \%$ and $57 \%$, respectively at 24 months. Another study also showed similar IOP reduction at 12 months in both DS (without collagen implant) and trabeculectomy. ${ }^{12}$ Chiselita et al ${ }^{13}$ looked at DS (without collagen implant) against trabeculectomy and showed trabeculectomy to be more effective at lowering IOP at 18 months. All published trials comparing these techniques suffer from lack of numbers, and comparisons with other trials using differing protocols and surgical technique are difficult.

Non-penetrating glaucoma surgery has been developed in an effort to offer a safer alternative to trabeculectomy in the management of medically uncontrolled glaucoma. In our study there was a higher incidence of early complications with trabeculectomy, 
Table 4 Early postoperative complications

\begin{tabular}{|c|c|c|c|c|c|c|c|}
\hline & $\begin{array}{c}\text { Hypotony } \\
(<6 \mathrm{~mm} \mathrm{Hg})\end{array}$ & Wound leak & Hyphaema & $\begin{array}{l}\text { Choroidal } \\
\text { detachment }\end{array}$ & $\begin{array}{l}\text { Hypotonous } \\
\text { maculopathy }\end{array}$ & $\begin{array}{c}\text { Fibrinous } \\
\text { AC }\end{array}$ & $\begin{array}{c}\text { Shallow } \\
\text { AC }\end{array}$ \\
\hline Trabeculectomy & $5(21 \%)$ & $10(42 \%)$ & 1 & 2 & 1 & 1 & 0 \\
\hline Viscocanalostomy & 0 & $8(32 \%)$ & 0 & 0 & 0 & 1 & 0 \\
\hline
\end{tabular}

when compared with viscocanalostomy. However, this had no long-term effect on IOP control or cataract formation. Our results suggest that trabeculectomy is more effective than viscocanalostomy at lowering IOP and maintaining long-term IOP control, but the same level of control can be achieved with viscocanalostomy if postoperative glaucoma treatment is restarted.

We are planning to continue following up our group of patients to see if there is a higher incidence of repeat procedures in the viscocanalostomy group, and to see if the addition of medication in this group is a long-term solution or if these patients are destined to fail completely at a later date. We may see better long-term results for non-penetrating glaucoma surgery as experience is gained in surgical technique and postoperative management. Our results support the view that when unaugmented surgery is indicated, trabeculectomy remains more effective than viscocanalostomy.

\section{Acknowledgements}

We thank Dr Victoria Allgar, Senior Lecturer (Medical Statistics) at Hull and York Medical School, for helping with the statistical analysis at first revision following Professor Jeremy Miles's departure to the United States. This work was presented at the Oxford Ophthalmological Congress 2006. No conflicting relationship exists between any of the authors and the subject matter of the study.

\section{References}

1 Cairns JE. Trabeculectomy. Preliminary report of a new method. Am J Ophthalmol 1968; 66(4): 673-679.

2 Simsek T, Citirik M, Batman A, Mutevelli S, Zilelioglu O. Efficacy and complications of releasable suture trabeculectomy and standard trabeculectomy. Int Ophthalmol 2005; 26(1-2): 9-14.
3 Stegmann R, Pienaar A, Miller D. Viscocanalostomy for open-angle glaucoma in black African patients. J Cataract Refract Surg 1999; 25(3): 316-322.

4 Miles J, Shevlin M. Applying Regression and Correlation. A Guide for Students and Researchers. Sage Publications: London, 2001.

5 Cairns JE. Trabeculectomy. Sub-title: 'a surgical method of reducing intra-ocular pressure in chronic simple glaucoma without sub-conjunctival drainage of aqueous humour'. Trans Ophthalmol Soc UK 1969; 88: 231-233.

6 O'Brart DP, Shiew M, Edmunds B. A randomised, prospective study comparing trabeculectomy with viscocanalostomy with adjunctive antimetabolite usage for the management of open angle glaucoma uncontrolled by medical therapy. Br J Ophthalmol 2004; 88(8): 1012-1017.

7 Shaarawy T, Nguyen C, Schnyder C, Mermoud A. Five year results of viscocanalostomy. Br J Ophthalmol 2003; 87(4): 441-445.

8 Yalvac IS, Sahin M, Eksioglu U, Midillioglu IK, Aslan BS, Duman S. Primary viscocanalostomy versus trabeculectomy for primary open-angle glaucoma: three-year prospective randomized clinical trial. J Cataract Refract Surg 2004; 30(10): 2050-2057.

9 Carassa RG, Bettin P, Fiori M, Brancato R. Viscocanalostomy versus trabeculectomy in white adults affected by open-angle glaucoma: a 2-year randomized, controlled trial. Ophthalmology 2003; 110(5): 882-887.

10 O'Brart DP, Rowlands E, Islam N, Noury AM. A randomised, prospective study comparing trabeculectomy augmented with antimetabolites with a viscocanalostomy technique for the management of open angle glaucoma uncontrolled by medical therapy. Br J Ophthalmol 2002; 86(7): 748-754.

11 Mermoud A, Schnyder CC, Sickenberg M, Chiou AG, Hediguer SE, Faggioni R. Comparison of deep sclerectomy with collagen implant and trabeculectomy in open-angle glaucoma. J Cataract Refract Surg 1999; 25(3): 323-331.

12 El Sayyad F, Helal M, El-Kholify H, Khalil M, El-Maghraby A. Nonpenetrating deep sclerectomy versus trabeculectomy in bilateral primary open-angle glaucoma. Ophthalmology 2000; 107(9): 1671-1674.

13 Chiselita D. Non-penetrating deep sclerectomy versus trabeculectomy in primary open-angle glaucoma surgery. Eye 2001; 15(Part 2): 197-201. 